\title{
ZnO Heteroepitaxy on Sapphire Using a Novel Buffer Layer of Titanium Oxide: Crystallographic Behavior
}

\author{
Satoshi Yamauchi ${ }^{*}$, Yoh Imai ${ }^{2}$ \\ ${ }^{1}$ Department of Biomolecular Functional Engineering, Ibaraki University, Hitachi, Japan \\ ${ }^{2}$ Department of Electric and Electronic Engineering, Ibaraki University, Hitachi, Japan \\ Email: ${ }^{*}$ ysatoshi@mx.ibaraki.ac.jp
}

Received October 31, 2012; revised January 2, 2013; accepted January 11, 2013

Copyright (C) 2013 Satoshi Yamauchi, Yoh Imai. This is an open access article distributed under the Creative Commons Attribution License, which permits unrestricted use, distribution, and reproduction in any medium, provided the original work is properly cited.

\begin{abstract}
A novel buffer layer consists of titanium oxide grown on a-sapphire by low-pressure chemical vapor deposition using titanum-tetra-iso-propoxide and oxygen gas was used for $\mathrm{ZnO}$ epitaxial growth at temperature as low as $340^{\circ} \mathrm{C}$ by plasma-assisted epitaxy using radio-frequency oxygen-gas plasma. XRD and RHEED indicated $(0001) \mathrm{Ti}_{2} \mathrm{O}_{3}$ layer in corundum crystal system was epitaxially grown on the substrate in an in-plane relationship of [1-100] $\mathrm{Ti}_{2} \mathrm{O}_{3} / /$ [0001] $\mathrm{Al}_{2} \mathrm{O}_{3}$ by uniaxial phase-lock system. Growth behavior of $\mathrm{ZnO}$ layer was significantly dependent on the $\mathrm{Ti}_{2} \mathrm{O}_{3}$ buffer-layer thickness, for example, dense columnar ZnO-grains were grown on the buffer layer thinner than $10 \mathrm{~nm}$ but the hexagonal pyramid-like grains were formed on the thin buffer layers below $2 \mathrm{~nm}$. RHEED observations showed $\mathrm{ZnO}$ layer including the pyramid-like grains was epitaxially grown with single-domain on the thin buffer layer of 0.8 $\mathrm{nm}$ in the in-plane relationship of $[1-100] \mathrm{ZnO} / /[1-100] \mathrm{Ti}_{2} \mathrm{O}_{3} / /[0001] \mathrm{Al}_{2} \mathrm{O}_{3}$, whereas the multi-domain was included in $\mathrm{ZnO}$ layer on the buffer layer above $10 \mathrm{~nm}$.
\end{abstract}

Keywords: $\mathrm{ZnO} ; \mathrm{Ti}_{2} \mathrm{O}_{3}$; Plasma-Assisted Epitaxy; Hexagonal Pyramid Grain

\section{Introduction}

$\mathrm{ZnO}$ has been candidate of interesting material for highly efficient blue or ultraviolet light-emitting devices because of the wide direct band gap of $3.37 \mathrm{eV}$ at room temperature and the large exciton binding energy of 60 $\mathrm{meV}$. However, it has been recognized that undoped$\mathrm{ZnO}$ shows highly n-type conductivity by native-defects such as interstitial-Zn and strong green emission due to oxygen deficiency, which are introduced by the high temperature growth and/or poor reactivity of supplied oxygen for the growth. Several advanced processes such as Moleculer-Beam Epitaxy (MBE) using oxygen-plasma cell [1], Metal-Organic MBE (MOMBE) using $\mathrm{H}_{2} \mathrm{O}$ vapor [2], Pulsed Laser Deposition (PLD) [3] etc. have been developed to reduce the native defects. Plasmaassisted epitaxy (PAE) using oxygen plasma excited by radio-frequency (rf) power is also useful to achieve $\mathrm{ZnO}$ epitaxial growth at low temperatures supplying reactive oxygen as demonstrated for undoped- $\mathrm{ZnO}$ growth at $400^{\circ} \mathrm{C}$ on c-sapphire [4,5] and Si [6]. In addition, acceptor-doping with sufficient dopant preventing the self-

${ }^{*}$ Corresponding author. compensation should be required to fabricate $\mathrm{p}$-type $\mathrm{ZnO}$ and the pn-junction. Nitrogen has been used for acceptor-doping into $\mathrm{ZnO}$ layer [2,7] including the co-doping [8], however, the heavily doped nitrogen-acceptor showed the large activation energy such as $224 \mathrm{meV}$ [9]. In contrast, relatively shallow nitrogen acceptor with the activation energy of $132 \mathrm{meV}$ was doped into $\mathrm{ZnO}$ layer by PAE using $\mathrm{O}_{2}+\mathrm{N}_{2}$ gas plasma with precise control of $\mathrm{O} / \mathrm{Zn}$ supply ratio during the growth [10]. Such features have been observed in the growth of other II-VI compound semiconductor such as $\mathrm{ZnSe}$ [11] and are originnated from self-compensation in the heavy acceptordoping by native donor-defects. For $\mathrm{ZnO}$ growth, the growth mode should be taken into account to control the doping since the layer has been grown on sapphire substrate with large lattice mismatching. Indeed, it was reported that the electron concentration is high in $\mathrm{ZnO}$ layers including three-dimensional grains and/or multi-domains [12], where the donor defects were probably come from interstitial-Zn formed on the three-dimensional surface with higher sticking coefficient of $\mathrm{Zn}$ on the steps and kinks. In general, suitable buffer layer is required for two-dimensional epitaxial growth in lattice mismatching 
system such as $\mathrm{ZnO} /$ sapphire to satisfy the relationship of $\sigma_{\mathrm{sv}}>\sigma_{\mathrm{sc}}+\sigma_{\mathrm{cv}}$ by reducing the interface energy, where $\sigma_{\mathrm{sv}}, \sigma_{\mathrm{sc}}$ and $\sigma_{\mathrm{cv}}$ are surface energy on the substrate, interface energy and surface energy of film respectively. For the purpose, Y. Chen et al. reported interest results to relax the lattice-mismatching by using an initial buffer layer of thin $\mathrm{MgO}$ layer with rocksalt crystal structure on c-sapphire, where the mismatch could be reduced to $9 \%$ comparing the large value of $18 \%$ on c-sapphire [13]. In the hetero-epitaxial system, initial $\mathrm{ZnO}$ layer grown at $500^{\circ} \mathrm{C}$ on the buffer layer was annealed at $750^{\circ} \mathrm{C}$ to reduce the surface roughness, and then single domain $\mathrm{ZnO}$ layer was epitaxially grown with smooth surface at $620^{\circ} \mathrm{C}$. However, it was also reported that the low temperature photoluminescence spectrum was improved but dominated by neutral donor-bound exciton emission at $3.369 \mathrm{eV}$, which indicates native donor was still included in the $\mathrm{ZnO}$ layer. In contrast, while $\mathrm{Ti}_{2} \mathrm{O}_{3}$ with corundum crystal structure is also an interesting material as the initial buffer layer, which is expected to reduce the lattice mismatch in the system of $(0001) \mathrm{ZnO} /(0001) \mathrm{Ti}_{2} \mathrm{O}_{3}$ as low as $5 \%$ with large surface energy on the $(0001) \mathrm{Ti}_{2} \mathrm{O}_{3}$, the heteroepitaxial system has not been studied because $\mathrm{Ti}_{2} \mathrm{O}_{3}$ single has not been established.

In this paper, we demonstrate epitaxial growth of $\mathrm{Ti}_{2} \mathrm{O}_{3}$ layer on a-sapphire by low-pressure chemical vapor deposition and then enhanced two-dimensional epitaxial growth of $\mathrm{ZnO}$ layer at the temperature as low as $340^{\circ} \mathrm{C}$ by $\mathrm{PAE}$ on the $\mathrm{Ti}_{2} \mathrm{O}_{3}$ buffer layer.

\section{Experimental}

Titanium oxide layer was grown in bell-jar type chamber at low temperature of $320^{\circ} \mathrm{C}$ in 3 mtorr on a-sapphire by LPCVD using titanium tetra-iso-propoxide (TTIP: Ti$\left.\left(\mathrm{OC}_{3} \mathrm{H}_{7}\right)_{4}\right)$ and oxygen gas. The liquid TTIP ( $97 \%$ purity) was vaporized in a quartz-cell at $70^{\circ} \mathrm{C}$ after purification in vacuum at $50^{\circ} \mathrm{C}$ for $3 \mathrm{hr}$, then the TTIP-gas was introduced into the growth chamber through a hot alumina nozzle at $85^{\circ} \mathrm{C}$ monitoring and controlling the pressure in the chamber using Schultz gage and a variable valve, where high-purity oxygen gas (6N-purity) was simultaneously supplied with the TTIP-gas but through the individual gas lines for precise control $\mathrm{O}_{2} /$ TTIP supply ratio. It is mentioned here that detection sensitivity in such ion-gage should be corrected for each gas species to determine the supply rate but the directly monitored pressure was used without the correction in this study because it is not easy to evaluate the sensitivity of the metal-organic gas catalyzed by the oxidant.

$\mathrm{ZnO}$ layer was grown at $340^{\circ} \mathrm{C}$ in 3 mtorr by plasmaassisted epitaxy (PAE) using oxygen gas plasma which was excited by $10 \mathrm{~W}$ rf-power at $13.56 \mathrm{MHz}$ using a capacitively coupled rf-electrode. Details of the PAE appa- ratus were described elsewhere [9]. High-purity elemental $\mathrm{Zn}$ (6N-up purity) and oxygen gas (6N purity) were used for $\mathrm{ZnO}$ growth. Elemental $\mathrm{Zn}$ (6N-up purity) was evaporated from a Knudsen cell with a nozzle to prevent oxidation of the surface and supplied to the growth surface through the oxygen gas plasma, where high-purity oxygen gas with $6 \mathrm{~N}$-purity was used. Effective $\mathrm{Zn} / \mathrm{O}$ supply ratio was determined by the dependence of $\mathrm{ZnO}$ growth rate on $\mathrm{Zn}$-supply rate [9].

$300 \mathrm{~m}$-thick single crystalline a- and c-sapphire with mirror surface used as substrates were cleaned in organic-solvents and hot $\mathrm{H}_{2} \mathrm{SO}_{4}+\mathrm{H}_{2} \mathrm{O}_{2}$ at $60^{\circ} \mathrm{C}$ for $5 \mathrm{~min}$, then, loaded into the chamber after rinse in ultra purewater with the resistivity above $18.2 \mathrm{M} \mathrm{cm}$ and blow by nitrogen-gas. In the case of substrate etching, a hot $3 \mathrm{H}_{2} \mathrm{SO}_{4}+\mathrm{H}_{3} \mathrm{PO}_{4}$ solution at $130^{\circ} \mathrm{C}$ was used as the etchant and the substrate treated by $\mathrm{H}_{2} \mathrm{SO}_{4}+\mathrm{H}_{2} \mathrm{O}_{2}$ was etched for $15 \mathrm{~min}$.

Thickness of the titanium-oxide layer and the $\mathrm{ZnO}$ layer were checked by a contact-type surface profiler, where the thickness of the thin titanium-oxide layer below $10 \mathrm{~nm}$ was estimated by the growth rate evaluated for the layer above $20 \mathrm{~nm}$-thickness and the period rate. Crystal-system and crystal-orientation was examined by a-2XRD measurement using $\mathrm{Cuk}_{1,2}$. Surface morphology of the $\mathrm{ZnO}$ films was observed by Nomarski differential interference microscope. Reflection high-energy electron diffraction (RHEED) system was also used on the surfaces of the layers and the substrate to disclose the surface structures and the in-plane epitaxial relationship.

\section{Results and Discussions}

\section{1. $\mathrm{Ti}_{2} \mathrm{O}_{3}$ Epitaxial Growth on A-Sapphire}

It is recognized that titanium-oxide growth using TTIP and $\mathrm{O}_{2}$ is owing to thermal catalysis of TTIP enhanced by the oxidation, therefore, the growth behavior includeing the crystallinity is significantly dependent on not only the growth temperature but also the supply ratio of $\mathrm{O}_{2}$ /TTIP [14]. As a typical result, FTIR results indicated that some types of impurities such as hydrocarbons and hydroxyls derived from the TTIP dissociation sequences were slightly remained in the layer by the low supply ratio below 1 but not detected in the layer grown by $\mathrm{O}_{2}$-rich conditions above 1.5 , therefore, the layer was grown in the large supply ratio of 8 to remove such impurities completely. On the other, it has also been recognized that titanium oxide compound can be crystallized in diverse compositions and crystal systems due to the hybrid-orbital of titanium including the d-orbital, where the valence of $\mathrm{Ti}$ is changed from 0.33 to 5.0. Tokita et al. reported (112) anatase- $\mathrm{TiO}_{2}$ with tetragonal crystal system can be epitaxially grown on c-sapphire at relatively low temperature about $500^{\circ} \mathrm{C}$ by atmospheric chemical 
vapor deposition using TTIP and $\mathrm{O}_{2}$ [15]. In contrast, we found out (0001) $\mathrm{Ti}_{2} \mathrm{O}_{3}$ with corundum in hexagonal system was epitaxially grown on a-sapphire by LPCVD as shown below. Figure 1 shows XRD profile of 400 nm-thick titanium-oxide layer grown on a-sapphire by LPCVD, where the diffraction corresponding to (0006) $\mathrm{Ti}_{2} \mathrm{O}_{3}$ was only appeared at $39.5^{\circ}$ [16] from the layer with some peaks from the substrate, which indicates preferentially (0001) oriented $\mathrm{Ti}_{2} \mathrm{O}_{3}$ layer was grown on the substrate. Figures 2(a) and (b) show RHEED patterns of the layer with the thickness of $10 \mathrm{~nm}$, where the electron beam was incident along [0001] $\mathrm{Al}_{2} \mathrm{O}_{3}$ and $[1-100] \mathrm{Al}_{2} \mathrm{O}_{3}$, respectively. It is noted that the patterns corresponding to (a) [1-100] and (b) $[-1-120] \mathrm{Ti}_{2} \mathrm{O}_{3}$ showed sixfold-symmetry because each pattern was repeated every $60^{\circ}$ and alternated every $30^{\circ}$ when the film was rotated with respect to the electron beam incident. The RHEED patterns showed the layer was three-dimensional growth but clearly indicated $(0001) \mathrm{Ti}_{2} \mathrm{O}_{3}$ layer was epitaxially grown on a-sapphire with an inplane relationship of [1-100] $\mathrm{Ti}_{2} \mathrm{O}_{3} / /[0001] \mathrm{Al}_{2} \mathrm{O}_{3}$. Representation of oxygen in the two surfaces can be shown as Figure 3, where the oxygen on $\mathrm{Al}_{2} \mathrm{O}_{3}$ and $\mathrm{Ti}_{2} \mathrm{O}_{3}$ surface is shown by open and closed circles, respectively. The symmetry of the oxygen arrangement between the two surfaces was different in each other, however, the distance of oxygen on $\mathrm{Ti}_{2} \mathrm{O}_{3}$ is periodically matched along $[1-100] \mathrm{Al}_{2} \mathrm{O}_{3}$, in which the threefold oxygen on $\mathrm{Ti}_{2} \mathrm{O}_{3}$ surface along [1100] $\mathrm{Ti}_{2} \mathrm{O}_{3}$ is just matched to the fivefold oxygen in $\mathrm{Al}_{2} \mathrm{O}_{3}$ along [1-100] $\mathrm{Al}_{2} \mathrm{O}_{3}$ with the mismatch less

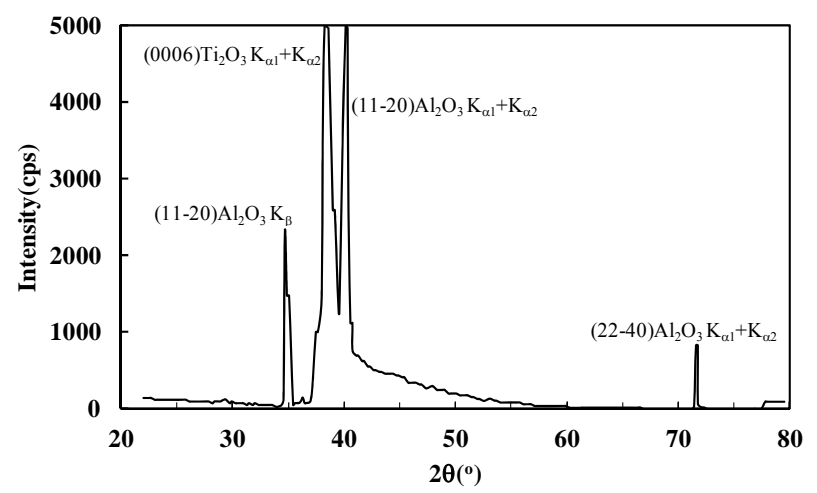

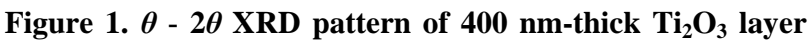
grown on a-sapphire by LPCVD.
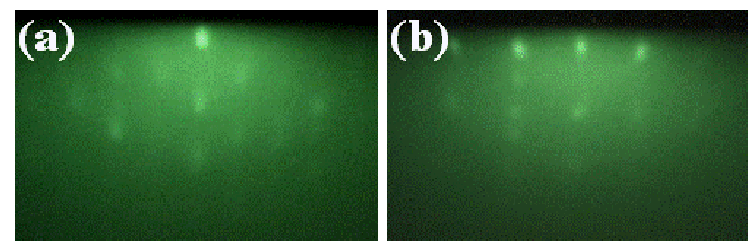

Figure 2. RHEED patterns on $\mathrm{Ti}_{2} \mathrm{O}_{3}$ layer grown on a-sapphire, where the electron beam was incident along (a) $[0001]$ and (b) $[1-100] \mathrm{Al}_{2} \mathrm{O}_{3}$.

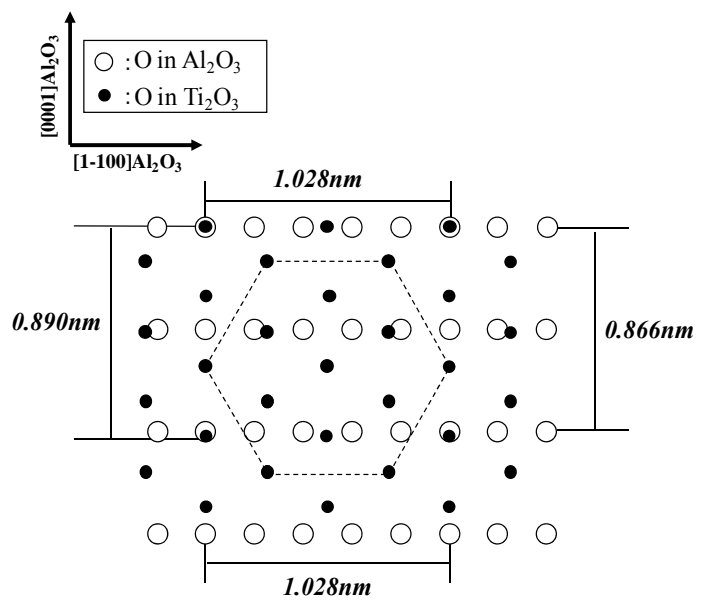

Figure 3. Representation of oxygen on a-sapphire (opencircles) and (0001) $\mathrm{Ti}_{2} \mathrm{O}_{3}$ (closed-circles) in the in-plane relationship of [1-100] $\mathrm{Ti}_{2} \mathrm{O}_{3} / /[0001] \mathrm{Al}_{2} \mathrm{O}_{3}$.

than $0.06 \%$ in addition to the relatively low mismatching of $2.8 \%$ along [0001] $\mathrm{Al}_{2} \mathrm{O}_{3}$. Previously, it was demonstrated that $(0001) \mathrm{ZnO}$ with sixfold-symmetry is locked by uniaxially matched oxygen along [0001] $\mathrm{Al}_{2} \mathrm{O}_{3}$ with twofold symmetric oxygen on a-sapphire surface [17]. Also in the $\mathrm{Ti}_{2} \mathrm{O}_{3}$ /a-sapphire system, it can be considered that $(0001) \mathrm{Ti}_{2} \mathrm{O}_{3}$ was locked by the asymmetry on a-sapphire surface along $[1-100] \mathrm{Al}_{2} \mathrm{O}_{3}$. The spotty RHEED patterns as shown in Figure 2 were significantly dependent on the layer thickness as shown in Figure 4, which showed RHEED patterns of (a) $2 \mathrm{~nm}$ - and (b) 0.8 nm-thick $\mathrm{Ti}_{2} \mathrm{O}_{3}$ layers, where the electron beam was incident along [1-100] $\mathrm{Al}_{2} \mathrm{O}_{3}$ as same as Figure 2(b). The spotty pattern from the relatively thick layer above $10 \mathrm{~nm}$ (Figure 2(b)) was changed to streak with decreasing the thickness below $2 \mathrm{~nm}$ and showed the fine Kikuchi-line on the $0.8 \mathrm{~nm}$-thick layer.

The sixfold symmetry observed for the $10 \mathrm{~nm}$-thick layer was same as the very thin layers, however, the streak-line distance for the $0.8 \mathrm{~nm}$-thick layer was slightly large (about $2 \%$ ) comparing to that for the thick layer, which suggested the layer was stressed by the lattice mismatch along [1-100] $\mathrm{Al}_{2} \mathrm{O}_{3}$. These results indicated the layer was two-dimensionally grown with slightly shrunk hexagonal unit at initial stage but three-dimensionally above the critical thickness probably within the lattice constant along c-axis $(1.364 \mathrm{~nm})$. The growth features can be considered that the layer was grown by Stranski-Krastanov mode [18], in which the energy relationship between the substrate and the layer is satisfied to be $\sigma_{\mathrm{sv}}>\sigma_{\mathrm{sc}}+\sigma_{\mathrm{cv}}$ for the thickness below the critical thickness but changed to be $\sigma_{\mathrm{sv}}<\sigma_{\mathrm{sc}}+\sigma_{\mathrm{cv}}$ for the layer thicker than the critical thickness, or secondary nucleation caused by dislocation in the layer grown on the lattice mismatched substrate. Of course, the growth behaveior of $\mathrm{Ti}_{2} \mathrm{O}_{3}$ layer including the critical thickness was 

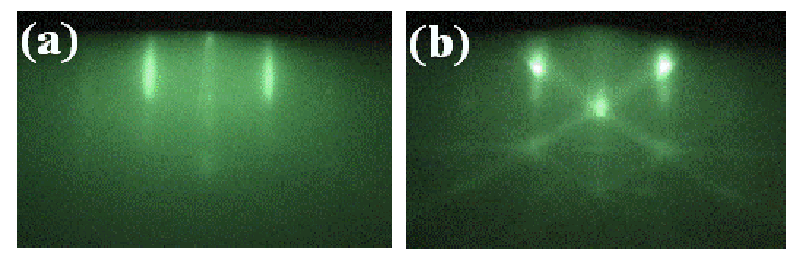

Figure 4. RHEED patterns of $\mathrm{Ti}_{2} \mathrm{O}_{3}$ layer with the thickness of (a) $2 \mathrm{~nm}$ and (b) $0.8 \mathrm{~nm}$ on a-sapphire, where the electron beam was incident along [1-100] $\mathrm{Al}_{2} \mathrm{O}_{3}$.

significantly influenced by the growth conditions such as the introduced gas rate, growth temperature and so on, and the thin layer with smooth surface as shown in Figure 4(b) could be grown in oxygen rich condition $\left(\mathrm{O}_{2} /\right.$ TTIP supply ratio above 8$)$ with the low growth rate about $0.3 \mathrm{~nm} / \mathrm{min}$ at $320^{\circ} \mathrm{C}$.

\subsection{ZnO Growth on $\mathrm{Ti}_{2} \mathrm{O}_{3}$ Buffer Layer}

\subsubsection{Surface Morphology}

Figure 5 shows Nomarski-photographs of PAE-ZnO layers with the thickness about $600 \mathrm{~nm}$ grown at $340^{\circ} \mathrm{C}$. Preferentially (0001) oriented $\mathrm{ZnO}$ layer consists of densely three-dimensional columnar grains was grown on csapphire (Figure 5(a)), however, the $30^{\circ}$-rotational domains with in-plane relationships of $[11-20] \mathrm{ZnO} / /[11-$ $20] \mathrm{Al}_{2} \mathrm{O}_{3}$ and $[10-10] \mathrm{ZnO} / /[11-20] \mathrm{Al}_{2} \mathrm{O}_{3}$ due to large lattice mismatch between (0001) $\mathrm{ZnO}$ and c-sapphire were included in the layer as reported elsewhere [19]. In contrast, polycrystalline $\mathrm{ZnO}$ layer with rough surface including (10-11) and (0001) oriented grains was grown on a-sapphire at the temperature as low as $340^{\circ} \mathrm{C}$ by $\mathrm{PAE}$, while single-crystalline (0001) ZnO layer was grown on a-sapphire at $500^{\circ} \mathrm{C}$ by radical source MBE using two step process demonstrated by the initial step for nucleation at $400^{\circ} \mathrm{C}$ and the in-situ annealing for the coalescence at $500^{\circ} \mathrm{C}$ [17]. It is considered that the growth behavior on a-sapphire by PAE was come from three-dimensional nucleation with the low density at the initial stage, which was resulted in textured three-dimensional grain growth and secondary nucleation in deep grain boundaries on the $\mathrm{ZnO}$ surface during the growth. In contrast, the feature on the $\mathrm{Ti}_{2} \mathrm{O}_{3}$ layer was quite differed as shown in Figures 5(c)-(e), where $\mathrm{ZnO}$ layer with the average thickness about $600 \mathrm{~nm}$ was grown at $340^{\circ} \mathrm{C}$. ZnO layer consists of highly dense columnar grains coming from high density nucleation on the $\mathrm{Ti}_{2} \mathrm{O}_{3}$ layer comparing to that on sapphires was grown on the buffer layer above $10 \mathrm{~nm}$ (Figure 5(c)), which speculated that the surface reactivity of the layer was higher than sapphire. Further, pyramid-shape grains with the hexagonal facets could be clearly observed in the $\mathrm{ZnO}$ layers on the thinner $\mathrm{Ti}_{2} \mathrm{O}_{3}$ layer than $2 \mathrm{~nm}$ and the density was decreased with decreasing the buffer layer thickness (Figures 5(d) and (e)). It is interesting that
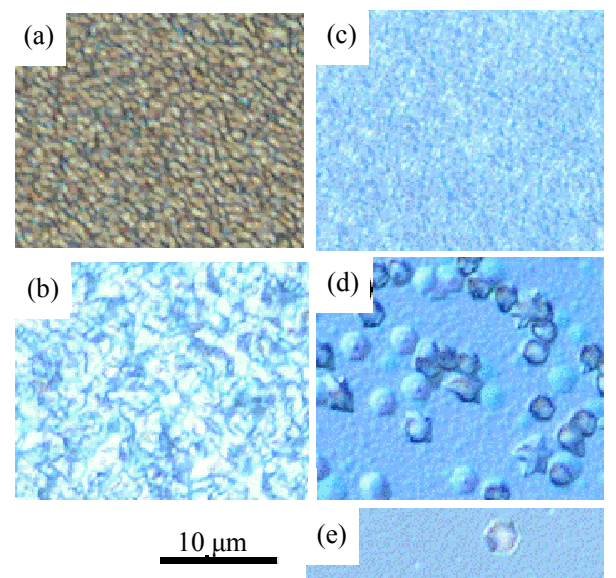

(e)
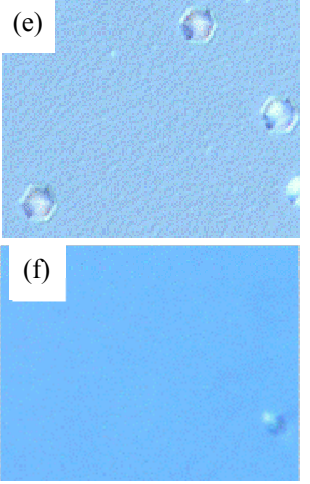

Figure 5. Surface morphologies observed by Nomarski microscope of $\mathrm{ZnO}$ layers on (a) c-sapphire, (b) a-sapphire, (c) $10 \mathrm{~nm}$-thick buffer layer, (d) 2 nm-thick buffer layer, (e) 0.8 nm-thick buffer layer on a-sapphire and (f) $0.8 \mathrm{~nm}$-thick buffer layer on a-sapphire etched by $3 \mathrm{H}_{2} \mathrm{SO}_{4}+\mathrm{H}_{3} \mathrm{PO}_{4}$ solution.

the small columnar-like grain was observed at center of the pyramid in the layer on $2 \mathrm{~nm}$-thick buffer layer (Figure 5(d)), which was expected the three-dimensional nuclei was firstly created at the initial stage and then the pyramid grain grew around the columnar-like grain, that is, the columnar-like grain was grown with significantly higher rate comparing to the smooth surface. The pyramid was also formed in $\mathrm{ZnO}$ layer on the $0.8 \mathrm{~nm}$-thick $\mathrm{Ti}_{2} \mathrm{O}_{3}$ layer but the columnar-like grain in the center could not be observed, which indicates growth rate of the columnar-like grain was lower than that on the $2 \mathrm{~nm}$ thick $\mathrm{Ti}_{2} \mathrm{O}_{3}$ layer. Figure 6 shows growth rates of $\mathrm{ZnO}$ layer on c-sapphire and the $0.8 \mathrm{~nm}$-thick buffer layer as a function of $\mathrm{Zn}$ evaporated rate from the cell during the growth in constant $\mathrm{O}_{2}$-supply rate and induced rf-power, where the growth rate was evaluated by the thickness of $\mathrm{ZnO}$ layer grown for 1 hour and the thickness on the buffer layer was checked on the smooth surface without the pyramids. In both cases, the growth rate was limited by the smaller supply rate of $\mathrm{Zn}$ or $\mathrm{O}$, which indicated the sticking coefficients of $\mathrm{Zn}$ on $\mathrm{Zn}$ and $\mathrm{O}$ on $\mathrm{O}$ were negligible in this condition, but obviously larger on c-sapphire than on the buffer layer. On the other, both of the saturated growth rate in the height and the $\mathrm{Zn}$-flux for 


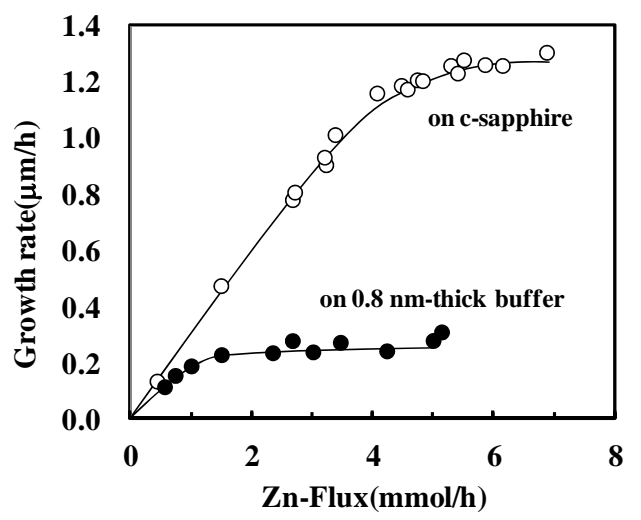

Figure 6. Growth rate of $\mathrm{ZnO}$ layer on c-sapphire and $\mathbf{0 . 8}$ nm-thick buffer layer.

the effective supply rate of $\mathrm{Zn} / \mathrm{O}=1$ were increased for the pyramids. In addition, the values were increased with the buffer thickness, for example, the pyramids were grown with the rate about $0.7 \mathrm{~m} / \mathrm{h}$ by the $\mathrm{Zn}$-flux above $2.5 \mathrm{~mm} / \mathrm{h}$ on the $0.8 \mathrm{~nm}$-thick layer but about $1 \mathrm{~m} / \mathrm{h}$ by the flux above $3.5 \mathrm{mmol} / \mathrm{h}$ on the $2 \mathrm{~nm}$-thick layer. It is noted here that the $\mathrm{ZnO}$ layer consists of columnar grains on the thick buffer layer above $10 \mathrm{~nm}$ was grown with the high rate comparable to that on c-sapphire. Previously, it was reported that growth rate of $\mathrm{ZnO}$ layer on $\mathrm{Zn}$-polar surface is higher than that on O-polar surface [20] because of the higher sticking coefficient of O-adatom on the $\mathrm{Zn}$-face than that of $\mathrm{Zn}$-adatom on the $\mathrm{O}$-face. If the high growth rate of the partially formed pyramid grain comparing to the other smooth area was originated from the growth faces, it is expected the grain could not be formed with the fine hexagonal facets and the in-plane size should be determined at initial growth stage of $\mathrm{ZnO}$, however, the grains showed the fine facets and the in-plane size were increased with the growth period. Therefore, it should be concluded that the high rate growth of the pyramid grains was not caused by difference of the polar on the growth surface but by the higher sticking coefficient of adatoms at the steps or the kinks than that on the terraces. The growth feature of the pyramid grain was also dependent on the surface condition of sapphire substrate, for example, the pyramid grain was almost disappeared by chemical etching of a-sapphire in a hot $3 \mathrm{H}_{2} \mathrm{SO}_{4}+\mathrm{H}_{3} \mathrm{PO}_{4}$ solution at $130^{\circ} \mathrm{C}$ for $15 \mathrm{~min}$. as shown in Figure 5(f), where the growth conditions and the thickness for $\mathrm{ZnO}$ and $\mathrm{Ti}_{2} \mathrm{O}_{3}$ layers were same as the sample in Figure 5(e). The result clearly indicated that some types of defect including surface roughness on the buffer layer could be removed by the etching.

\subsubsection{Epitaxial Relationship}

Figure 7 show RHEED patterns corresponding to (a) [1-210] and (b) [-1010] $\mathrm{ZnO}$ on the $\mathrm{ZnO}$ layer shown in Figure 5(e) when the electron beam was incident along

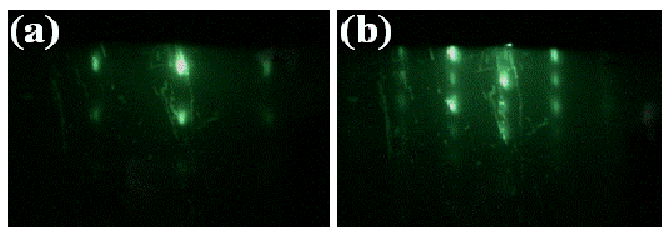

Figure 7. RHEED patterns of ZnO layer on 0.8 nm-thick buffer layer when the electron beam was incident along (a) [0001] and (b) [1-100] $\mathrm{Al}_{2} \mathrm{O}_{3}$.

[0001] and [1-100] $\mathrm{Al}_{2} \mathrm{O}_{3}$, respectively. The each pattern was repeated every $60^{\circ}$ and alternated every $30^{\circ}$ as the film was rotated with respect to the electron beam incident. The patterns clearly indicated that the $\mathrm{ZnO}$ layer was epitaxially grown without rotational domains on the buffer layer, whereas the layer was including hexagonal pyramids. [1-210] of the hexagonal pyramids as shown in Figure 5(e) was also coincident to $[0001] \mathrm{Al}_{2} \mathrm{O}_{3}$. These results investigate the three-dimensional nuclei were partially formed with the same in-plane epitaxial relationship of the two-dimensional growth surface. As a result, the in-plane pyramid size could be increased with the growth period. The growth behavior is seemed that the $\mathrm{ZnO}$ layer was grown by two growth modes of Frank-van der Merwe [17] (two-dimensional growth) and VolmerWeber [18] (three-dimensional pyramid grain growth). It is considered that the three-dimensional nuclei might be originated from the surface defects of buffer layer, which was come from sapphire-substrate, and prevented by the surface treatment of the substrate such as the high-temperature annealing.

Figures 8(a) and (b) show schematic representations of oxygen on (0001) $\mathrm{Ti}_{2} \mathrm{O}_{3}$ and $(0001) \mathrm{ZnO}$ surfaces, where the oxygen-atoms on $\mathrm{Ti}_{2} \mathrm{O}_{3}$ and $\mathrm{ZnO}$ were shown by closed- and open-circle with the unit cell by dot-line and solid-line hexagon based on the a-axis lattice constant of $0.324 \mathrm{~nm}$ and $0.514 \mathrm{~nm}$ for $\mathrm{ZnO}$ and $\mathrm{Ti}_{2} \mathrm{O}_{3}$, respectively. In the case of $[1-210] \mathrm{ZnO} / /[1-100] \mathrm{Ti}_{2} \mathrm{O}_{3}$ (Figure 8(a)), hexagon unit of the $\mathrm{ZnO}$ is larger than subunit hexagon of the $\mathrm{Ti}_{2} \mathrm{O}_{3}$ (about $+9.2 \%$ ), which is much smaller than that between $(0001) \mathrm{ZnO} /(0001) \mathrm{Al}_{2} \mathrm{O}_{3}$ in the relationship of $[1-210] \mathrm{ZnO} / /[1-100] \mathrm{Al}_{2} \mathrm{O}_{3}$ (more than $+18 \%$ ). In contrast, the mismatch between the $\mathrm{ZnO}$ and the $\mathrm{Ti}_{2} \mathrm{O}_{3}$ with in-plane relationship of $[1-100] \mathrm{ZnO} / /$ [1-100] $\mathrm{Ti}_{2} \mathrm{O}_{3}$ as shown in Figure 8(b) is reduced to $-5.4 \%$ which is better than that in $[1-210] \mathrm{ZnO} / /[1-$ 100] $\mathrm{Ti}_{2} \mathrm{O}_{3}$, therefore, the in-plane epitaxial relationship resulted in $[1-100] \mathrm{ZnO} / /[1-100] \mathrm{Ti}_{2} \mathrm{O}_{3}$. It is noted here that the mismatches between the $\mathrm{ZnO}$ and the 0.8 nm-thick $\mathrm{Ti}_{2} \mathrm{O}_{3}$ layer were expected to be smaller (about $2 \%$ ) than the values because the hexagon unit at the 0.8 nm-thick $\mathrm{Ti}_{2} \mathrm{O}_{3}$ surface was slightly smaller than that of the bulk but the mismatch is estimated to be above $3 \%$, however, the mismatch was still larger than that of $(0001) \mathrm{ZnO} /(0001) \mathrm{Al}_{2} \mathrm{O}_{3}$ in the relationship of $[1-100] \mathrm{ZnO}$ 


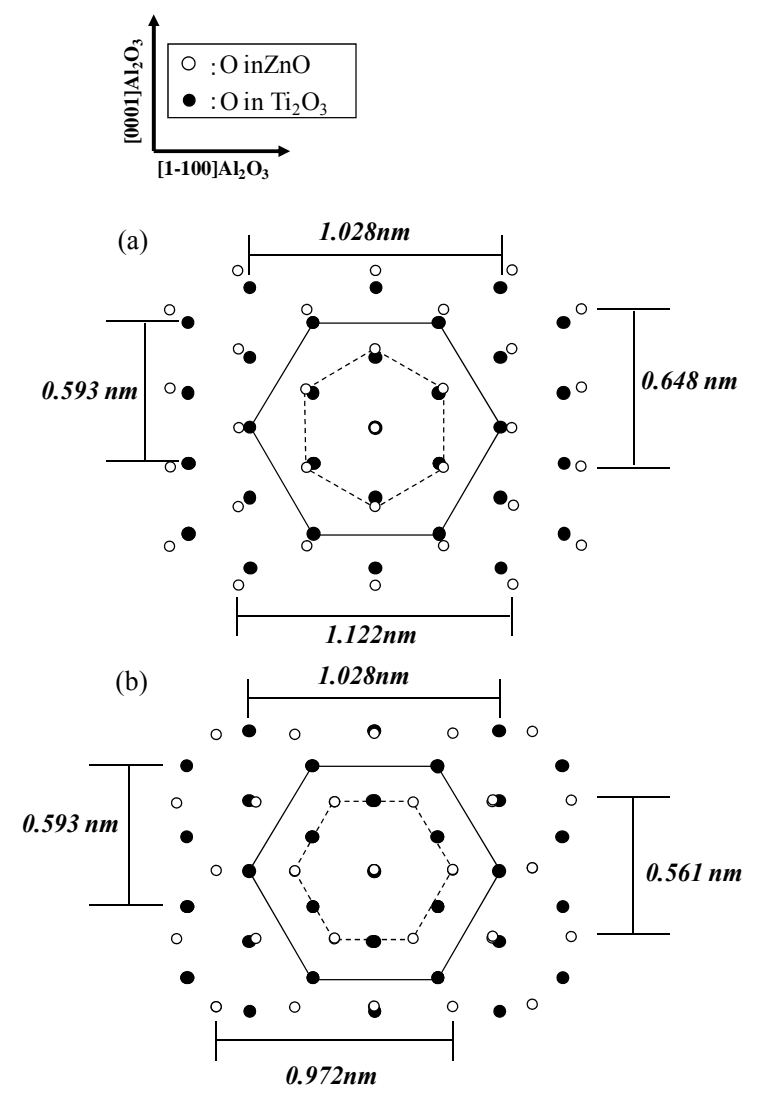

Figure 8. Representation of oxygen on $(0001) \mathrm{Ti}_{2} \mathrm{O}_{3}$ (closedcircles) and (0001)ZnO (open-circles) in the in-plane relationship of (a) [1-210]ZnO//[1-100]Ti $\mathrm{O}_{2}$ and (b) [1-100]ZnO $/ /[1-100] \mathrm{Ti}_{2} \mathrm{O}_{3}$.

$/ /[1-100] \mathrm{Al}_{2} \mathrm{O}_{3}$ (about $-2.3 \%$ ). It has been commonly recognized that the phase-locking without rotational domain is difficult on c-sapphire with the isotropic hexagonal surface, but the results in this study indicated the phase could be successfully locked on the isotropic hexagonal surface of $\mathrm{Ti}_{2} \mathrm{O}_{3}$ layer. The useful results for $\mathrm{ZnO}$ growth on the buffer layer can be concluded that the phase-locking is performed not only by the latticematching but also by control of the surface chemistry on the mismatching substrate such as $\mathrm{Ti}_{2} \mathrm{O}_{3}$.

\section{Conclusion}

PAE-ZnO growth at low temperature of $340^{\circ} \mathrm{C}$ was demonstrated on a-sapphire using a novel buffer layer consists of $\mathrm{Ti}_{2} \mathrm{O}_{3}$. (0001) $\mathrm{Ti}_{2} \mathrm{O}_{3}$ layer was epitaxially grown by LPCVD using TTIP and $\mathrm{O}_{2}$ on a-sapphire in the in-plane relationship of $[1-100] \mathrm{Ti}_{2} \mathrm{O}_{3} / /[0001] \mathrm{Al}_{2} \mathrm{O}_{3}$ at $320^{\circ} \mathrm{C}$. Surface roughness of the $\mathrm{Ti}_{2} \mathrm{O}_{3}$ layer was increased with the thickness, however, extremely smooth surface could be obtained on thin buffer layer below 1 $\mathrm{nm}$-thickness. The $\mathrm{ZnO}$ layer could be epitaxally grown with single domain in the in-plane relationship of [1$100] \mathrm{ZnO} / /[1-100] \mathrm{Ti}_{2} \mathrm{O}_{3}$ on the thin buffer layer. Hexago- nal pyramid-shape $\mathrm{ZnO}$ grains by three-dimensional epitaxial growth were formed on the thin buffer layer in the in-plane epitaxial relationship with the significant high growth rate comparing to the two-dimensional growth. It was suggested from growth feature of the pyramid grains that epitaxial relationship in the three-dimensional growth was same as the two-dimensional growth and the high growth rate of the pyramid was caused by high sticking coefficient of adatoms on the three-dimensional surface. The number of the pyramid-grains could be obviously reduced by chemical wet etching of a-sapphire using hot $3 \mathrm{H}_{2} \mathrm{SO}_{4}+\mathrm{H}_{3} \mathrm{PO}_{4}$ solution. The total-epitaxial relationship was revealed as $[1-100] \mathrm{ZnO} / /[1-100] \mathrm{Ti}_{2} \mathrm{O}_{3} / /[0001] \mathrm{Al}_{2} \mathrm{O}_{3}$ by RHEED observations. These crystallographic results can be concluded that $\mathrm{Ti}_{2} \mathrm{O}_{3}$ layer is a promised candidate for the buffer layer to achieve high-quality $\mathrm{ZnO}$ growth at low temperatures.

\section{REFERENCES}

[1] M. A. L. Johnson, et al., "MBE Growth and Properties of $\mathrm{ZnO}$ on Sapphire and SiC Substrates," Journal of Electronic Materials, Vol. 25, No. 5, 1996, pp. 855-862. doi:10.1007/BF02666649

[2] A. B. M. A. Ashrafi, et al., "Nitrogen-Doped p-Type ZnO Layers Prepared with $\mathrm{H}_{2} \mathrm{O}$ Vapor-Assisted Metalorganic Molecular-Beam Epitaxy," Japanese Journal of Applied Physics, Vol. 41, 2002, pp. L1281-L1284. doi:10.1143/JJAP.41.L1281

[3] R. D. Vispute, et al., "High Quality Crystalline ZnO Buffer Layers on Sapphire(001) by Pulsed Laser Deposition for III-V Nitrides," Applied Physics Letters, Vol. 70, No. 20, 1997, pp. 2735-2737. doi:10.1063/1.119006

[4] S. Yamauchi, et al., "Low Temperature Epitaxial Growth of $\mathrm{ZnO}$ Layer by Plasma-Assisted Epitaxy," Thin Solid Films, Vol. 345, No. 1, 1999, pp. 12-17. doi:10.1016/S0040-6090(99)00096-6

[5] S. Yamauchi, et al., "Plasma-Assisted Epitaxial Growth of ZnO Layer on Sapphire," Journal of Crystal Growth, Vol. 214-215, 2000, pp. 63-67. doi:10.1016/S0022-0248(00)00060-9

[6] S. Yamauchi, et al., "Surface Treatment of Si Using Hydrogen-Plasma to Improve Optoelectronic Property of $\mathrm{ZnO}$ on (111)Si," Japanese Journal of Applied Physics, Vol. 44, 2005, pp. 7801-7804. doi:10.1143/JJAP.44.7801

[7] K. Minegishi, et al., "Growth of p-Type Zinc Oxide Films by Chemical Vapor Deposition," Japanese Journal of Applied Physics, Vol. 36, 1997, pp. L1453-L1455. doi:10.1143/JJAP.36.L1453

[8] M. Joseph, et al., "p-Type Electrical Conduction in $\mathrm{ZnO}$ Thin Films by Ga and N Codoping," Japanese Journal of Applied Physics, Vol. 38, 2001, pp. L1205-L1207. doi:10.1143/JJAP.38.L1205

[9] D. C. Look, et al., "Characterization of Homoepitaxial p-Type ZnO Grown by Molecular Beam Epitaxy," Applied Physics Letters, Vol. 81, No. 10, 2002, pp. 1830- 
1832. doi:10.1063/1.1504875

[10] S. Yamauchi, et al., "Photoluminescence Studies of Undoped and Nitrogen-Doped $\mathrm{ZnO}$ Layers Grown by Plasma-Assisted Epitaxy," Journal of Crystal Growth, Vol. 260, No. 1-2, 2006, pp. 1-6. doi:10.1016/j.jcrysgro.2003.08.002

[11] I. S. Hauksson, et al., "Compensation Processes in Nitrogen Doped ZnSe," Applied Physics Letters, Vol. 61, No. 18, 1992, pp. 2208-2210. doi:10.1063/1.108296

[12] A. Ohtomo, et al., "Lateral Grain Size and Electron Mobility in ZnO Epitaxial Films Grown on Sapphire Substrates," Journal of Crystal Growth, Vol. 214-215, 2000, pp. 284-288. doi:10.1016/S0022-0248(00)00093-2

[13] Y. Chen, et al., "Layer-by-Layer Growth of $\mathrm{ZnO}$ Epilayer on $\mathrm{Al}_{2} \mathrm{O}_{3}(0001)$ by Using a $\mathrm{MgO}$ Buffer Layer," Applied Physics Letters, Vol. 76, No. 5, 2000, pp. 559-561. doi:10.1063/1.125817

[14] K. H. Ahna, et al., "Kinetic and Mechanistic Study on the Chemical Vapor Deposition of Titanium Dioxide Thin Films by in Situ FT-IR Using TTIP," Surface and Coatings Technology, Vol. 171, No. 1-3, 2003, pp. 198-204. doi:10.1016/S0257-8972(03)00271-8

[15] S. Tokita, et al., "High-Rate Epitaxy of Anatase Films by Atmospheric Chemical Vapor Deposition," Japanese
Journal of Applied Physics, Vol. 39, 2000, pp. L169L171. doi:10.1143/JJAP.39.L169

[16] S. Weisssmann, et al., "Selected Powder Diffraction Data for Metals and Alloys," JCPDS, Card No. 10-63, 1978, p. 298.

[17] K. Nakahara, et al., "Growth of Undoped ZnO Films with Improved Electrical Properties by Radical Source Molecular Beam Epitaxy," Japanese Journal of Applied Physics, Vol. 40, 2001, pp. 250-254. doi:10.1143/JJAP.40.250

[18] T. Fukuda and H. J. Scheel, "Crystal Growth Technology," Wiley, New York, 2003.

[19] I. Ohkubo, et al., "In-Plane and Polar Orientations of $\mathrm{ZnO}$ Thin Films Grown on Atomically Flat Sapphire," Surface Science, Vol. 443, 1999, pp. L1043-L1048. doi:10.1016/S0039-6028(99)01024-9

[20] H. Kato, et al., "High-Quality ZnO Epilayers Grown on Zn-Face ZnO Substrates by Plasma-Assisted Molecular Beam Epitaxy," Journal of Crystal Growth, Vol. 265, No. 3-4, 2004, pp. 375-381. doi:10.1016/j.jcrysgro.2004.02.021 